\title{
Global Sensitivity Analysis of In-plane Elastic Buckling of Steel Arches
}

\author{
Trong-Ha Nguyen \\ Department of Civil Engineering \\ Vinh University \\ Vinh, Vietnam \\ trongha@vinhuni.edu.vn
}

\begin{abstract}
Steel arches are widely used in civil engineering and industrial structures. Their response depends on material properties, geometric dimensions, and boundary conditions. The objective of the current study is to perform global sensitivity analysis, and to assess the influence of random input parameters on the in-plane elastic buckling of steel arches. The in-plane elastic buckling load of steel arches under uniform compression proposed in previous studies is adopted. The influence of the random input variables of the structure is evaluated using Sobol's global sensitivity analysis. Monte Carlo simulation is also employed to rank the influence of input random variables.
\end{abstract}

Keywords-in-plane elastic buckling; steel arches; sensitivity; global sen sitivity; Sobol' indices; Monte Carlo simulation

\section{INTRODUCTION}

Global sensitivity consists of the individual sensitivity of each variable and its interaction with other variables. Sobol's sensitivity index is widely applied in the structural engineering field [1-5]. Steel structures often present high durability while including slender components. Sensitivity and reliability analyses for steel structures have been conducted by many researchers [6-12]. Steel arches are widely used in civil engineering and industrial structures. Arches resist external loadings by a combination of predominant axial compression and bending actions. The geometry of circular steel arches is shown in Figure 1, and the uniform compression on the steel arches is shown in Figure 2. If the steel arches are adequately designed with lateral bracings so that their out-of-plane failure is fully prevented, in-plane buckling failure may occur $[13,14]$. The in-plane elastic buckling is important in the stability design of metal arch structures [15]. The in-plane elastic buckling of shallow arches with an arbitrary cross-section was investigated and the in-plane elastic buckling load of shallow arches was found to be much lower than that given by the classical theory $[16,17]$. Moreover, the classical in-plane buckling load should not be used as the reference load in the development of design methods for the in-plane strength of shallow steel arches.

This paper studies the sensitivity assessment of the input random variables on the in-plane elastic buckling load of the steel arches under uniform compression. An algorithm using the global sensitivity method is proposed for utilization in analyses and assessments. The in-plane elastic buckling load of steel arches under uniform compression has been proposed in
[14]. In addition, the effects of input random variables on the in-plane elastic buckling load of the steel arches under uniform compression are also examined.

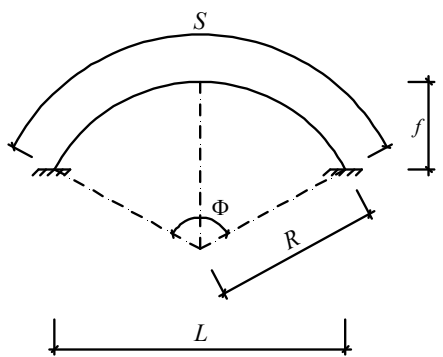

Fig. 1. Geometry of the arches.

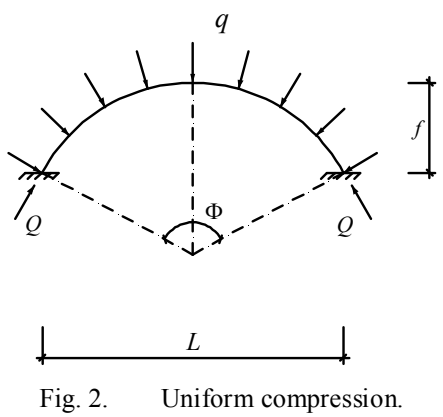

\section{THEORETICAL FRAMEWORK}

\section{A. In-plane Elastic Buckling of Steel Arches}

In this section, the buckling load of arches proposed in [14] is presented. Arches with an included angle $\Phi<90^{\circ}$ are considered as shallow arches and the dimensionless parameter $\lambda$ is defined as:

$$
\lambda=\frac{S \Phi}{4 r_{x}}
$$

where $S$ is the length of the arch, $r_{x}=\sqrt{I / A}$ is the radius of gyration of the cross-section, $I$ is the second moment of the area of the cross-section about its major principal axis, and $A$ is the area of the cross-section. 
The buckling load of the pin-ended shallow arch can be defined as in (2) and the buckling load of the fixed shallow arch is expressed as in (3):

$$
\begin{aligned}
& N_{a c r}= \begin{cases}\left(0.15+0.006 \lambda^{2}\right) N_{c r} ; & \text { for } 3.88<\lambda<9.38 \\
\left(0.26+0.74 \sqrt{1-0.63 \pi^{4} / \lambda^{2}}\right) N_{c r} ; & \text { for } \lambda>9.38\end{cases} \\
& N_{a c r}=\left\{\begin{array}{l}
\left(0.36+0.0011 \lambda^{2}\right) N_{c r} ; \quad \text { for } 9.87<\lambda<18.6 \\
\left(0.6+0.4 \sqrt{1-3.109 \pi^{4} / \lambda^{2}}\right) N_{c r} ; \text { for } \lambda>18.6
\end{array}\right.
\end{aligned}
$$

When an arch has an included angle $\Phi>90^{\circ}$, it is considered to be a deep arch, and its elastic buckling load is given by [14]:

$$
\begin{gathered}
N_{a c r}=\left[1-(\Phi / \pi)^{2}\right] N_{c r} ; \text { for pin-ended arches } \\
N_{a c r}=\left[1-(\Phi / 1.4304 \pi)^{2}\right] N_{c r} ; \text { for fixed arches }
\end{gathered}
$$

where $N_{c r}$ is the second mode elastic flexural buckling load of a corresponding fixed or pin-ended column with the same length. $N_{c r}$ is determined as:

$$
N_{c r}=\frac{\pi^{2} E I}{(k S)^{2}}, \text { with } k= \begin{cases}0.5 ; & \text { for pin-ended arches } \\ 0.35 & \text { for fixed arches }\end{cases}
$$

where $E$ is the Young's modulus and $I$ is the second moment of the area of the cross-section about its major principal axis.

\section{B. Global Sensitivity Analysis}

Sensitivity presents the influence of input design parameters (i.e. variables) $\boldsymbol{X}=\left(X_{1}, X_{2}, \ldots, X_{m}\right)$ on the output model $\boldsymbol{Y}=f(\boldsymbol{X})$. Here, $\boldsymbol{X}=\left(X_{1}, X_{2}, \ldots, X_{m}\right)$ is the vector of design parameters in $\mathbb{R}^{m}$ space and $\boldsymbol{Y}=\left(Y_{1}, Y_{2}, \ldots, Y_{n}\right)$ is the vector of output value in $\mathbb{R}^{n}$ space. Let us consider an integral function $\boldsymbol{Y}=f(\boldsymbol{X})$ which can be decomposed into elementary functions, expressed as [5]:

$$
\begin{gathered}
f(\boldsymbol{X})=f_{0}+\sum_{i} f_{i}\left(X_{i}\right)+\sum_{i<j} f_{i j}\left(X_{i}, X_{j}\right)+\cdots \\
\cdots+f_{1 \cdots m}\left(X_{1}, \ldots, X_{m}\right)
\end{gathered}
$$

where $X_{i}$ represents the input random variables with independent probability while the variance of the output variable can be expressed as $[4,5,18]$ :

$$
\operatorname{Var}[Y]=\sum_{i=1}^{m} V_{i}+\sum_{1 \leq i<j \leq m}^{m} V_{i j}+\ldots+V_{1 \ldots m}
$$

where

$$
V_{i}=\operatorname{Var}\left[E\left[Y \mid X_{i}\right]\right] ; V_{i j}=\operatorname{Var}\left[E|Y| X_{i} X_{j}\right]-V_{i}-V_{j}
$$

$$
V_{1 \ldots n}=\operatorname{Var}[Y]-\sum_{i=1}^{m} V_{i}-\sum_{1 \leq i<j \leq m}^{m} V_{i j}-\sum_{1 \leq i_{1}<\ldots<i_{n-1} \leq m}^{m} V_{i_{1} \ldots i_{m-1}}
$$

The first-order Sobol's indices are determined by:

$$
S_{i}=V_{i} / \operatorname{Var}[Y]
$$

The second-order Sobol's indices are determined by:

$$
S_{i}=V_{i j} / \operatorname{Var}[Y]
$$

The total-order Sobol's indices are then determined by:

$$
S_{T i}=S_{i}+S_{i j}+S_{i k l}+\ldots+S_{i \ldots n}
$$

The Sobol's indices are commonly estimated with the Monte Carlo method [19, 20]. In this research, the Sobol's indices of global sensitivity with Monte Carlo simulation are established with the use of Matlab, the flowchart of the procedure is shown in Figure 3.

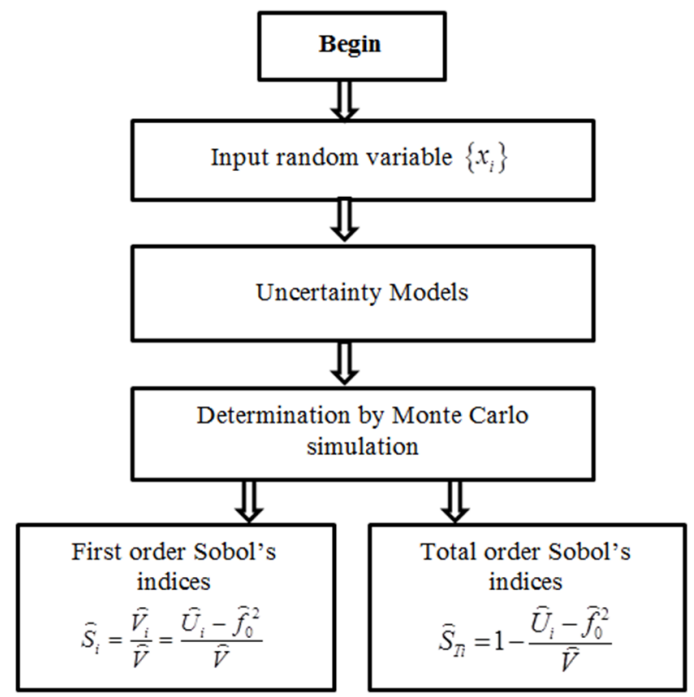

Fig. 3. Flowchart of the Sobol's indices sensitivity analysis by Monte Carlo simulation.

\section{MethodOLOGY}

\section{A. Safe Condition}

According to [14], the safe condition of the in-plane elastic buckling load of steel arches, determined by (3)-(5), can be rewritten as follows:

$$
N_{s a f} \leq N_{a c r}
$$

where $N_{s a f}$ is the external load, which can fluctuate randomly.

\section{B. Deterministic Model and Uncertainty Model}

Deterministic model is the above buckling analysis problem, in which the input parameters are those of geometry $\left(S, B, D, t_{w}, t_{f}, L, \Phi\right)$ and the Young's modulus of elasticity of 
steel $(E)$. This model can be written in the form of $\boldsymbol{X}=\left[S, B, D, t_{w}, t_{f}, E, L, \Phi\right]:$

$$
N_{a c r}=\mathfrak{I}(\boldsymbol{X})
$$

The uncertainty model is constructed based on the deterministic model by taking into account the randomness of input parameters. The parameters assumed to be random are $\boldsymbol{X}=\left[S(\omega), B(\omega), D(\omega), t_{w}(\omega), t_{f}(\omega), E(\omega), L(\omega), \Phi(\omega)\right]$, where $\omega$ represents the randomness of the parameters. This model can be written as:

$$
N_{a c r}(\omega)=\mathfrak{I}(\boldsymbol{X}(\omega))
$$

\section{Global Analysis by Monte Carlo Simulation}

Sensitivity analysis for in-plane elastic buckling load of the steel arches has been performed using the global sensitivity, which is based on Sobol's sensitivity indices. Monte Carlo simulation is established with the use of Matlab. The flowchart is shown in Figure 4.

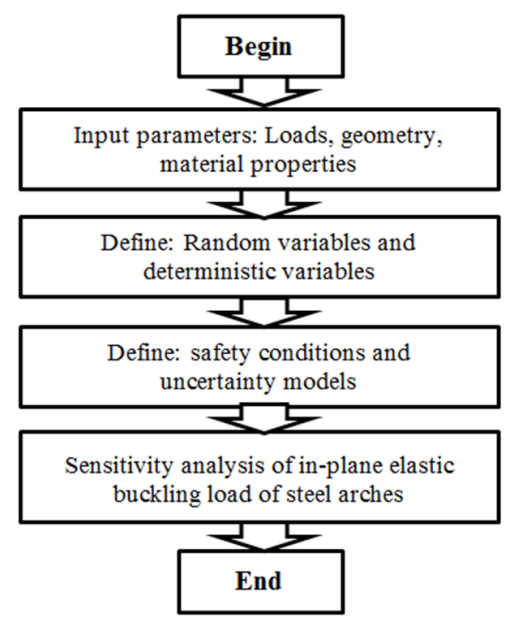

Fig. 4. Flowchart of the sensitivity analysis for in-plane elastic buckling load of steel arches based on the Sobol's indices of global sensitivity by Monte Carlo simulation.

\section{NUMERICAL RESULTS}

A. Validation of the Matlab Code of Sobol's Indices Sensitivity Analysis

In order to validate the Matlab code of the Sobol's indices of global sensitivity by Monte Carlo simulation, a test function, namely Ishigami's function was employed, defined as [21]:

$$
Y(X)=\sin X_{1}+7 \sin ^{2} X_{2}+\frac{1}{10} X_{3}^{4} \sin X_{1}
$$

where $X_{1}, X_{2}, X_{3}$ are uniform distributions between $-\pi$ and $\pi$. The numerical results are shown in Table I. A comparison with the results from [5] implies the reliability of the proposed program.
TABLE I. MEAN ESTIMATION WITH 10,000 MONTE CARLO SAMPLES OF FIRST AND TOTAL SOBOL'S INDICES

\begin{tabular}{|c|c|c|c|c|c|c|c|}
\hline \multirow{2}{*}{$\boldsymbol{X}_{\mathbf{i}}$} & \multicolumn{2}{c|}{ Proposed code } & \multicolumn{2}{c|}{ Result in [5] } & \multicolumn{2}{c|}{ Error (\%) } \\
\cline { 3 - 8 } & $\boldsymbol{S}_{\boldsymbol{i}}$ & $\boldsymbol{S}_{\boldsymbol{T i}}$ & $\boldsymbol{S}_{\boldsymbol{i}}$ & $\boldsymbol{S}_{\boldsymbol{T i}}$ & $\boldsymbol{S}_{\boldsymbol{i}}$ & $\boldsymbol{S}_{\boldsymbol{T i}}$ \\
\hline 1 & $X_{1}$ & 0.315 & 0.577 & 0.313 & 0.576 & 0.63 & 0.17 \\
\hline 2 & $X_{2}$ & 0.432 & 0.440 & 0.434 & 0.438 & 0.46 & 0.45 \\
\hline 3 & $X_{3}$ & 0.001 & 0.258 & 0.001 & 0.254 & 0.00 & 1.55 \\
\hline
\end{tabular}

\section{B. Sensitivity Analysis of In-plane Elastic Buckling Load of} Steel Arches

Global sensitivity based on Sobol's sensitivity indices was applied to evaluate the influence of input random variables on the in-plane elastic buckling load of steel arches under uniform compression. The input parameters are divided in two cases:

Case study 1: The in-plane elastic buckling load of the fixed steel arches under uniform compression with input parameters $S, B, D, t_{w}, t_{f}, E, L, \Phi$.

Case study 2: The in-plane elastic buckling load of the pinended steel arches under uniform compression with input parameters $S, B, D, t_{w}, t_{f}, E, L, \Phi$.

\section{1) Case Study 1}

The fixed steel arch under uniform compression is shown in Figure 5. The input variables are shown in Table II. Global sensitivity based on Sobol's sensitivity indices is applied to evaluate the influence of input random variables on the inplane elastic buckling load of the fixed steel arches under uniform compression. After 100,000 simulations in 67.0 minutes, the results of Sobol's sensitivity indices are shown in Table III and Figure 6.

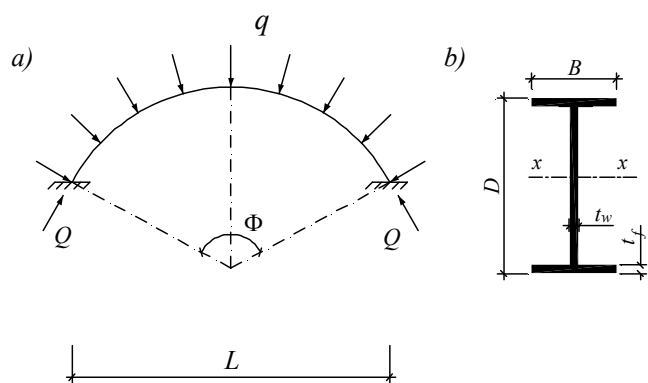

Fig. 5. The fixed steel arches under uniform compression and the crosssection of the arch.

TABLE II. STATISTICAL PROPERTIES OF RANDOM VARIABLES FOR SOBOL'S INDICES SENSITIVITY ANALYSIS

\begin{tabular}{|c|c|c|c|c|}
\hline Properties & Variables & Distribution & Range & Units \\
\hline \multirow{3}{*}{ Geometry } & $S$ & Uniform & $/ 6.283-7.679 /$ & $\mathrm{m}$ \\
\cline { 2 - 5 } & $L$ & Uniform & $/ 9.00-10.00 /$ & $\mathrm{m}$ \\
\cline { 2 - 5 } & $\Phi$ & Uniform & $/ 0.628-0.768 /$ & $\mathrm{Rad}$ \\
\hline Material & $E$ & Uniform & $/ 18 \mathrm{E} 5-22 \mathrm{E} 5 /$ & $\mathrm{Mpa}$ \\
\hline \multirow{3}{*}{$\begin{array}{c}\text { Cross- } \\
\text { section }\end{array}$} & $D$ & Uniform & $/ 0.235-0.287 /$ & $\mathrm{m}$ \\
\cline { 2 - 5 } & $B$ & Uniform & $/ 0.136-0.166 /$ & $\mathrm{m}$ \\
\cline { 2 - 5 } & $t_{\mathrm{w}}$ & Uniform & $/ 0.007-0.008 /$ & $\mathrm{m}$ \\
\cline { 2 - 5 } & $t_{\mathrm{f}}$ & Uniform & $/ 0.011-0.014 /$ & $\mathrm{m}$ \\
\hline
\end{tabular}


TABLE III. MEAN ESTIMATION WITH 100,000 MONTE CARLO SAMPLES OF FIRST AND TOTAL SOBOL'S INDICES

\begin{tabular}{|c|c|c|}
\hline & 1st order effects & Total effects \\
\hline$X_{1}(S)$ & 0.2942 & 0.2819 \\
\hline$X_{2}(E)$ & 0.0795 & 0.0690 \\
\hline$X_{3}(D)$ & 0.6577 & 0.6510 \\
\hline$X_{4}(B)$ & 0.0425 & - \\
\hline$X_{5}\left(t_{\mathrm{w}}\right)$ & 0.0425 & - \\
\hline$X_{6}\left(t_{\mathrm{f}}\right)$ & 0.0425 & - \\
\hline$X_{7}(\Phi)$ & 0.0425 & - \\
\hline$X_{8}(L)$ & 0.0425 & - \\
\hline
\end{tabular}

(a)

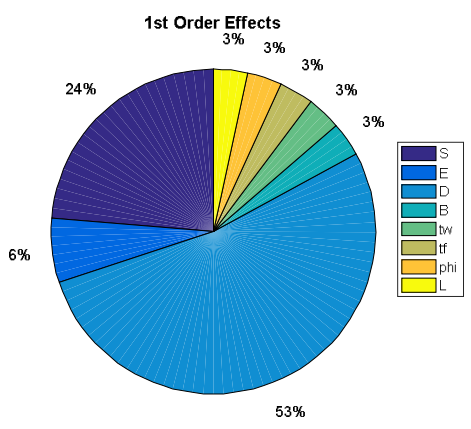

Total Effects

(b)

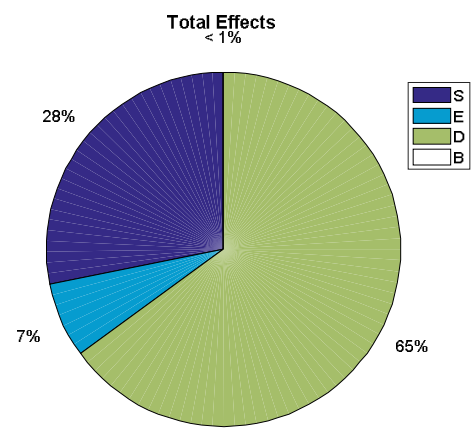

Fig. 6. (a) First order and (b) total Sobol's sensitivity indices of the fixed steel arches under uniform compression.

Table III and Figure 6 show the influence of input random variables on the in-plane elastic buckling load of the fixed steel arches under uniform compression based on Sobol's sensitivity indices. It can be seen that $S, E$ and $D$ are the most influential input random variables with proportions of $24.0 \%, 6.0 \%$, and $53.0 \%$ of the first-order Sobol's sensitivity indices, respectively and the total order sensitivity indices are $28.0 \%, 7.0 \%$, and $65.0 \%$, respectively. Meanwhile, the least influential input random variables are $B, t_{w}, t_{f}, L$ and $\Phi$ with a proportion of $3.0 \%$. This is consistent with the qualitative concept and that means the importance of sensitivity analysis of the in-plane elastic buckling load of the fixed steel arches under uniform compression.

\section{2) Case Study 2}

The input variables are shown in Figure 7 and Table II. Global sensitivity based on Sobol's sensitivity indices was applied to evaluate the influence of the input variables on the in-plane elastic buckling load of the pin-ended steel arches under uniform compression. The results after 100,000 simulations in 69.0 minutes are shown in Table IV and Figure 8 .

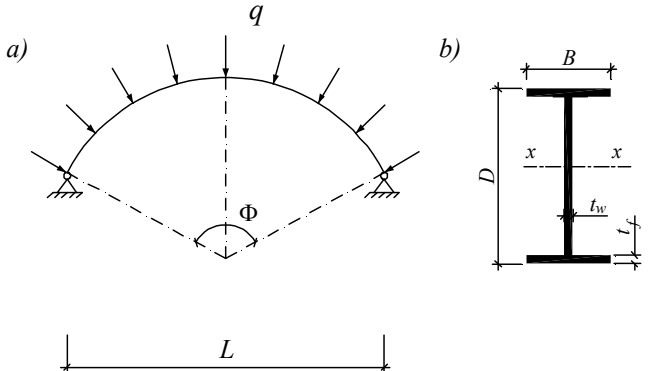

Fig. 7. The pin-ended steel arches under uniform compression and the cross-section of the arch.

(a)

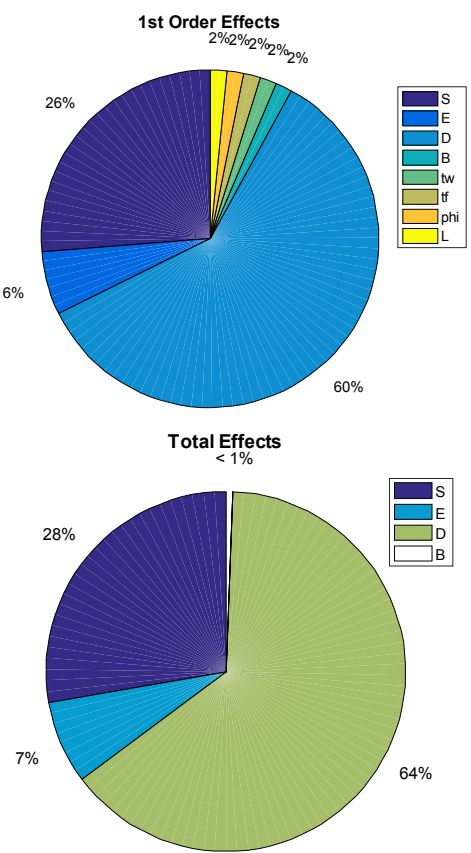

Fig. 8. (a) First order and (b) total Sobol's sensitivity indices of the pinended steel arches under uniform compression.

TABLE IV, MEAN ESTIMATION WITH 100,000 MONTE CARLO SAMPLES OF FIRST AND TOTAL SOBOL'S INDICES

\begin{tabular}{|c|c|c|}
\hline & 1st order effects & Total effects \\
\hline$X_{1}(S)$ & 0.2337 & 0.2788 \\
\hline$X_{2}(E)$ & 0.0472 & 0.0738 \\
\hline$X_{3}(D)$ & 0.6611 & 0.6844 \\
\hline$X_{4}(B)$ & 0.2337 & - \\
\hline$X_{5}\left(t_{\mathrm{w}}\right)$ & - & - \\
\hline$X_{6}\left(t_{\mathrm{f}}\right)$ & - & - \\
\hline$X_{7}(\Phi)$ & - & - \\
\hline$X_{8}(L)$ & - & - \\
\hline
\end{tabular}

Table IV and Figure 8 show the influence of the input variables on the in-plane elastic buckling load of the pin-ended steel arches under uniform compression based on Sobol's sensitivity indices. It can be seen from Table IV and Figure 9 that $S, E$ and $D$ are the most influential input random variables with proportions of $26.0 \%, 6.0 \%$ and $60.0 \%$ of the first order Sobol's sensitivity indices, respectively and the total order sensitivity indices are $28.0 \%, 7.0 \%$ and $64.0 \%$ respectively. 
Meanwhile, the least influential input random variables are $B$, $t_{w}, t_{f}, L$ and $\Phi$ with a proportion of $2.0 \%$.

From the above case studies, it can be seen that Sobol's sensitivity indices of random input variables on the in-plane elastic buckling load of steel arches condition of the fixed and pin-ended steel arches under uniform compression are not significant. The input random variables have a high sensitivity including $S, E$, and $D$. The obtained results show the significance of this research.

\section{CONCLUSIONS}

This paper proposed an algorithm to assess the structural sensitivity of the in-plane elastic buckling load of steel arches. The numerical process is developed based on Sobol's sensitivity indices and Monte Carlo simulation. The in-plane elastic buckling load of steel arches condition of the fixed and pin-ended steel arches under uniform compression is considered in the structural sensitivity assessment. From the numerical analysis, the flowing conclusions can be drawn:

- The algorithm is based on Sobol's sensitivity indices and Monte Carlo simulation and is developed for the sensitivity analysis of steel arches. A verification of the proposed algorithm is conducted using the Ishigami's test function.

- The developed procedure can be applied for the in-plane elastic buckling load of steel arches as an important recommendation for the selection of the input random variables based on numerical analysis.

- An extended application for other types of structures is highly feasible, however additional numerical tests and verifications are required.

\section{ACKNOWLEDGMENT}

This research was funded by the Vinh University. The authors declare that they have no potential conflicts of interest in this paper.

\section{REFERENCES}

[1] D. G. Cacuci, "Sensitivity theory for nonlinear systems. I. Nonlinear functional analysis approach," Journal of Mathematical Physics, vol. 22, no. 12, pp. 2794-2802, Dec. 1981, https://doi.org/10.1063/1.525186.

[2] H. Abshari, M. R. E. Azadi, and M. S. Azar, "Reliability Analysis of Steel Structures under Buckling Load in Second-order Theory," Advances in Research, pp. 950-966, Aug. 2014, https://doi.org/10.9734/ AIR/2014/11358.

[3] N. T. Ha and D. X. Hung, "Sensitivity analysis of the design portal frames of steel industrial buildings," MATEC Web of Conferences, vol. 193, 2018, Art. no. 04025, https://doi.org/10.1051/matecconf/ 201819304025.

[4] R. E. Melchers, "The effect of corrosion on the structural reliability of steel offshore structures," Corrosion Science, vol. 47, no. 10, pp. 23912410, Oct. 2005, https://doi.org/10.1016/j.corsci.2005.04.004.

[5] J. Morio, "Global and local sensitivity analysis methods for a physical system," European Journal of Physics, vol. 32, no. 6, pp. 1577-1583, Oct. 2011, https://doi.org/10.1088/0143-0807/32/6/011.

[6] X. H. Dang, "Identification de la variabilité spatiale des champs de contraintes dans les agrégats polycristallins et application à l'approche locale de la rupture," Ph.D. Thesis, Université Blaise Pascal, France.

[7] A. B. Owen, "Variance Components and Generalized Sobol' Indices," SIAM/ASA Journal on Uncertainty Quantification, vol. 1, no. 1, pp. 1941, Jan. 2013, https://doi.org/10.1137/120876782.
[8] J. H. Dshalalow, Advances in Queueing Theory, Methods, and Open Problems, 1st ed. Boca Raton, FL, USA: CRC Press, 1995.

[9] N.-L. Tran, T.-H. Nguyen, and V.-P. Phan, "Reliability assessment of Buckling Strength for Battened Built-up Columns steel considering shear deformations," IOP Conference Series: Materials Science and Engineering, vol. 869, Jul. 2020, Art. no. 052041, https://doi.org/ $10.1088 / 1757-899 X / 869 / 5 / 052041$.

[10] H. T. Nguyen, "Reliability assessment of frame steel considering semirigid connections," Journal of Materials and Engineering Structures, vol. 6, no. 1, pp. 119-126, Mar. 2019.

[11] N. L. Tran and T. H. Nguyen, "Reliability Assessment of Steel Plane Frame's Buckling Strength Considering Semi-rigid Connections," Engineering, Technology \& Applied Science Research, vol. 10, no. 1, pp. 5099-5103, Feb. 2020, https://doi.org/10.48084/etasr.3231.

[12] M. Rohani, G. Shafabakhsh, A. Haddad, and E. Asnaashari, "Sensitivity Analysis of Workspace Conflicts According to Changing Geometric Conditions," Engineering, Technology \& Applied Science Research, vol. 7, no. 1, pp. 1429-1435, Feb. 2017, https://doi.org/10.48084/etasr.1012.

[13] Y.-L. Pi and N. S. Trahair, "Out-of-Plane Inelastic Buckling and Strength of Steel Arches," Journal of Structural Engineering, vol. 124, no. 2, pp. 174-183, Feb. 1998, https://doi.org/10.1061/(ASCE)07339445(1998)124:2(174).

[14] Y.-L. Pi, M. A. Bradford, and B. Uy, "In-plane stability of arches," International Journal of Solids and Structures, vol. 39, no. 1, pp. 105125, https://doi.org/10.1016/S0020-7683(01)00209-8.

[15] T. V. Galambos, Ed., Guide to Stability Design Criteria for Metal Structures, 5th ed. New York, NY, USA: Wiley, 1998.

[16] S. P. Timoshenko and J. M. Gere, Theory of Elastic Stability, 2nd ed. edition. Mineola, NY, USA: Dover Publications, 2009.

[17] A. Mirmiran and A. M. Wolde-Tinsae, "Buckling and Postbuckling of Prestressed Sandwich Arches," Journal of Structural Engineering, vol. 119, no. 1, pp. 262-278, Jan. 1993, https://doi.org/10.1061/(ASCE) 0733-9445(1993)119:1(262)

[18] C. Zhang, J. Chu, and G. Fu, "Sobol"s sensitivity analysis for a distributed hydrological model of Yichun River Basin, China," Journal of Hydrology, vol. 480, pp. 58-68, Feb. 2013, https://doi.org/ 10.1016/j.jhydrol.2012.12.005.

[19] I. M. Sobol', "Global sensitivity indices for nonlinear mathematical models and their Monte Carlo estimates," Mathematics and Computers in Simulation, vol. 55, no. 1, pp. 271-280, Feb. 2001, https://doi.org/ 10.1016/S0378-4754(00)00270-6.

[20] A. Saltelli, "Making best use of model evaluations to compute sensitivity indices," Computer Physics Communications, vol. 145, no. 2, pp. 280 297, May 2002, https://doi.org/10.1016/S0010-4655(02)00280-1.

[21] T. Ishigami and T. Homma, "An importance quantification technique in uncertainty analysis for computer models," in [1990] Proceedings. First International Symposium on Uncertainty Modeling and Analysis, College Park, MD, USA, Dec. 1990, pp. 398-403, https://doi.org/ 10.1109/ISUMA. 1990.151285. 